\title{
INFLUÊNCIA DA TEMPERATURA, UMIDADE E PROFUNDIDADE DO SOLO NA PERSISTÊNCIA DO DIUROM E SULFATO DE ENDOSSULFAM EM UM SOLO TROPICAL
}

\author{
Flávia de Amorim Silva*, Carolina Lourencetti e Eliana Freire Gaspar de Carvalho Dores \\ Departamento de Química, Instituto de Ciências Exatas e da Terra, Universidade Federal de Mato Grosso, Av. Fernando Correa, \\ s/n, 78060-900 Cuiabá - MT, Brasil
}

Recebido em 3/9/09; aceito em 6/4/10; publicado na web em 20/7/10

\begin{abstract}
INFLUENCE OF TEMPERATURE, SOIL HUMIDITY AND SOIL DEPTH ON THE PERSISTENCE OF DIURON AND ENDOSULFAN SULFATE IN A TROPICAL SOIL. The influence of temperature $\left(30\right.$ and $\left.40{ }^{\circ} \mathrm{C}\right)$ and soil humidity $(20,50$ and $70 \%$ of water holding capacity) on the degradation of the herbicide diurom and the endosulfan metabolite, endosulfan sulfate was studied under laboratory conditions, in different soil layers (0-30, 30-38 and 38-83 cm) of an Oxisol (Yellow Latosol) collected in an agricultural area of Mato Grosso State, Brazil. Endosulfan sulfate was rapidly degraded under lower soil humidity, higher temperature and deeper soil layers. For diurom the opposite was observed as a consequence of its higher water solubility and lower soil sorption coefficient.
\end{abstract}

Keywords: degradation; pesticide; Latosol.

\section{INTRODUÇÃ̃o}

O Estado de Mato Grosso apresenta importante participação na produção agrícola nacional e possui uma extensa área com cultivo de espécies de elevado valor econômico, como o algodão, a soja e o milho. ${ }^{1}$ Embora pesticidas sejam utilizados para a manutenção dos altos níveis de produtividade dessas culturas no Estado, o elevado uso dos mesmos pode afetar organismos não alvos e atingir outros compartimentos ambientais, como águas superficial e subterrânea. ${ }^{2}$

Diurom e endossulfam são dois dos pesticidas mais frequentemente utilizados nas culturas de grãos e algodão na região centrooeste do Brasil e são também comumente usados em muitas partes do mundo. ${ }^{3-7}$ Devido a problemas ambientais e elevada toxicidade, o endossulfam, classificado como extremamente tóxico pela ANVISA, ${ }^{8}$ foi proibido em alguns países, incluindo os Estados Unidos e União Europeia, ${ }^{9,10}$ e recentemente uma consulta aos países membros do convênio está sendo realizada para classificação desta substância como poluente orgânico persistente e sua inserção na lista prioritária do Convênio de Estocolmo sobre Poluentes Orgânicos Persistentes. ${ }^{11}$

Diversos estudos apresentados na literatura descrevem o comportamento do diurom em regiões temperadas. Esse herbicida é considerado estável no intervalo de $\mathrm{pH}$ geralmente encontrados nos solos agricultáveis, ${ }^{12} \mathrm{e}$ apresenta resistência à fotólise em rios e águas do mar. ${ }^{13}$ Embora diversas bases de dados, que contemplam as características físicas e químicas de herbicidas, ${ }^{14}$ apresentem a sorção do diurom como moderada quando comparada com outros herbicidas, o mesmo é caracterizado como potencial contaminante de águas subterrâneas. ${ }^{7,15,16} \mathrm{Um}$ dos principais fatores preocupantes relacionados à presença do diurom no ambiente é a toxicidade desse composto, classificado como medianamente tóxico pela ANVISA, ${ }^{17}$ e de seus produtos de degradação, principalmente o 3,4-DCA (3,4-dicloroanilina). O diurom é um herbicida sistêmico e inibidor de fotossíntese em plantas. Essa substância vem sendo encontrada em amostras de água superficial e subterrânea de países como Inglaterra, Itália e Estados Unidos. ${ }^{18-20}$

De acordo com a sua classe de uso, o endossulfam é classificado como acaricida, inseticida e formicida. No Brasil, o endossulfam possui autorização para uso agrícola em aplicação foliar nas culturas de algodão,

*e-mail: flavia.amorimsilva@gmail.com cacau, café, cana-de-açúcar e soja. ${ }^{8}$ Os produtos comerciais apresentam uma mistura de dois isômetros, alfa- e beta-endossulfam nas proporções aproximadas de 70 e $30 \%$, respectivamente. Os isômeros sofrem rápida oxidação microbiológica, produzindo o sulfato de endossulfam. ${ }^{21,22} \mathrm{O}$ produto de degradação sulfato de endossulfam é altamente tóxico ao ambiente, particularmente para organismos aquáticos, ${ }^{23,24}$ e apresenta maior toxicidade e persistência do que o composto parental. Devido à baixa solubilidade em água e alta sorção ao solo, ${ }^{25,26}$ a contaminação de água subterrânea por sulfato de endossulfam não é esperada. Entretanto, esse produto de degradação tem sido detectado com frequência em águas subterrâneas (particularmente em aquíferos freáticos) de regiões de cultura de algodão, no Estado de Mato Grosso e em outros países como Canadá, ${ }^{27-29}$ Índia, ${ }^{30,31}$ Turquia, ${ }^{32}$ Malásia e Portugal, ${ }^{33,34}$ onde há uso intensivo do composto parental, endossulfam. Além disso, em solos altamente estruturados pode ocorrer o transporte por fluxo preferencial, que contribui para a rápida lixiviação de pesticidas, principalmente dos apolares, ${ }^{35}$ como é o caso do sulfato de endossulfam.

Além das propriedades físicas e químicas dos pesticidas e das condições climáticas do local de uso, outros fatores influenciam no destino de pesticidas no ambiente, como a contaminação dos recursos hídricos. ${ }^{36}$ Como apresentado por esses mesmos autores, a mobilidade e persistência de pesticidas em solo são dois importantes parâmetros que podem ser utilizados para avaliar o potencial risco de contaminação das águas superficial e subterrânea.

A persistência de pesticidas no solo é fortemente afetada pelas propriedades físicas e químicas do solo, com especial ênfase para o teor de matéria orgânica e mineral, e por condições como a temperatura e umidade..$^{37,38}$ Alguns estudos têm demonstrado que tais parâmetros, incluindo a profundidade do solo, apresentam importantes impactos na taxa de degradação do diurom e do sulfato de endossulfam no solo. ${ }^{5,39}$ Embora a literatura ressalte a necessidade da avaliação do comportamento de pesticidas em regiões tropicais, ${ }^{40}$ poucos estudos têm sido realizados neste sentido. ${ }^{3,4}$

Considerando a importância da avaliação do comportamento de pesticidas e produtos de degradação em regiões tropicais, o presente estudo teve por objetivo avaliar a influência da variação da temperatura e da umidade do solo sobre a degradação do herbicida diurom e do produto de degradação sulfato de endossulfam, sob condições controladas de laboratório, em diferentes profundidades de um Latossolo Amarelo coletado em uma região agrícola do Estado de Mato Grosso. 


\section{PARTE EXPERIMENTAL}

\section{Amostragem e tratamento das amostras de solo}

Amostras compostas de um Latossolo Amarelo foram coletadas em três diferentes profundidades, $0-30,30-38$ e $38-83 \mathrm{~cm}$, em uma área localizada nas coordenadas $15^{\circ} 25^{\prime} 07^{\prime \prime}$ de latitude Sul e $54^{\circ}$ 32' 16" de longitude Oeste, na micro bacia do córrego Chico Nunes, pertencente ao município de Dom Aquino - Mato Grosso. As amostras foram embaladas em sacos plásticos, identificadas e levadas para o laboratório de Análises de Resíduos de Pesticidas da Universidade Federal de Mato Grosso sob refrigeração, onde foram homogeneizadas e conservadas sob refrigeração $\left(6^{\circ} \mathrm{C}\right)$. Seguindo recomendações do procedimento $307 \mathrm{da}$ OECD ${ }^{41}$ as amostras foram mantidas nessas condições em um período inferior a 3 meses antes do seu uso.

A caracterização física e química das amostras do solo foi realizada no Laboratório de Solos da Universidade Federal de Mato Grosso, seguindo os métodos descritos em EMBRAPA..$^{42}$ As propriedades das amostras dos solos coletadas em três profundidades estão apresentadas na Tabela 1 .

Tabela 1. Propriedades físicas e químicas do Latossolo Amarelo

\begin{tabular}{lcccccc}
\hline $\begin{array}{l}\text { Camadas } \\
\mathrm{cm}\end{array}$ & Argila & $\begin{array}{r}\text { Silte } \\
\mathrm{g} \mathrm{kg}^{-1}\end{array}$ & Areia & $\begin{array}{c}\mathrm{pH} \\
\mathrm{H} \mathrm{O}\end{array}$ & $\begin{array}{c}\text { Carbono Orgânico } \\
\%\end{array}$ & $\mathrm{~g} \mathrm{~kg}^{-1}$ \\
\hline $0-30$ & 274 & 203 & 523 & 5,9 & 2,82 & 28,2 \\
$30-38$ & 417 & 60 & 524 & 5,3 & 2,11 & 21,1 \\
$38-83$ & 450 & 26 & 524 & 5,2 & 1,68 & 16,8 \\
\hline
\end{tabular}

\section{Reagentes}

Todos os solventes utilizados, metanol, acetonitrila, acetato de etila, diclorometano, hexano, tolueno e acetona, foram da marca Mallinckrodt Baker (Paris, KY, USA) grau HPLC. Os padrões analíticos do sulfato de endossulfam $(97,7 \%)$ e do diurom $(99,5 \%)$ foram da marca Pestanal (C. O. O., Alemanha). Cloreto de sódio (PA) e sulfato de sódio anidro (PA) foram obtidos da Quemis (Brasil). O adsorvente utilizado, SDVB (estireno divinil benzeno) foi obtido da Supelco (Supelclean ENVI-Chrom P) e o gás de arraste nitrogênio ultrapuro 5.0 (99,999\%) foi obtido da Linde Gás (Brasil).

\section{Instrumentação analítica}

A identificação e quantificação do sulfato de endossulfam foram realizadas utilizando um cromatógrafo a gás modelo HP 6890 com detector de captura de elétrons (CG-DCE), equipado com uma coluna capilar HP5-MS (5\% fenilmetilsiloxano), 30,0 m x $250 \mu$ m diâmetro interno $\mathrm{x} 0,25 \mu \mathrm{m}$ de espessura de fase estacionária. $\mathrm{O}$ volume de injeção foi de $1 \mu \mathrm{L}$ e nitrogênio foi empregado como gás de arraste. A vazão do gás na coluna e make-up foi 1,0 e 20,0 mL min ${ }^{-1}$, respectivamente. A programação da temperatura do forno consistiu de temperatura inicial igual a $92{ }^{\circ} \mathrm{C}(2,5 \mathrm{~min})$, aquecimento de $15{ }^{\circ} \mathrm{C}$ $\min ^{-1}$ até $175^{\circ} \mathrm{C}(13 \mathrm{~min})$, seguido de aquecimento a $280^{\circ} \mathrm{C}$ a $20^{\circ} \mathrm{C}$ $\mathrm{min}^{-1}$, sendo esta última temperatura mantida por $10 \mathrm{~min}$. As temperaturas do injetor e do detector foram 250 e $300^{\circ} \mathrm{C}$, respectivamente.

Foi empregado um cromatógrafo a líquido de alta eficiência (Varian, USA) equipado com autoamostrador modelo 410, bomba quaternária modelo 240, detector de arranjo de diodos modelo 330 e controlado pelo software Varian ProStar versão 5.5 (Varian) para identificação e quantificação do diurom. As condições cromatográficas utilizadas foram: coluna cromatográfica $(250 \times 4,6 \mathrm{~mm}$ I.D. $)$ e pré-coluna $(20 \times 4,6 \mathrm{~mm}$ I.D.) $\mathrm{C} 18 \mathrm{com}$ partículas de $5 \mu \mathrm{m}$ (Omnisphere), volume de injeção igual a $10 \mu \mathrm{L}$, gradiente de eluição, com vazão de $1 \mathrm{~mL} \mathrm{~min}^{-1}$, constando da mistura de dois solventes, água e acetonitrila, programados inicialmente com $40 \%$ de água e $60 \%$ de acetonitrila até os $6 \mathrm{~min}, 20$ e $80 \%$ aos $10 \mathrm{~min}, 100 \%$ de acetonitrila aos 12 min, permanecendo nessa condição até os 15 min. Foi utilizado o comprimento de onda no valor de $230 \mathrm{~nm}$ para a aquisição dos cromatogramas.

\section{Preparo das soluções e das suspensões de trabalho para fortificação das amostras de solo}

As soluções e suspensões para fortificação das amostras foram preparadas a partir dos padrões analíticos do pesticida diurom e do metabólito sulfato de endossulfam. As concentrações das mesmas foram de 9,09 e 6,14 $\mu \mathrm{g} \mathrm{mL}^{-1}$ para as condições de umidade de 50 e $70 \%$ da capacidade de campo, respectivamente. Considerando a baixa solubilidade em água das substâncias estudadas, pequeno volume de solvente orgânico foi utilizado para auxiliar na solubilização das mesmas. A solubilidade, bem como outras propriedades físicas e químicas do diurom e do sulfato de endossulfam estão apresentadas na Tabela 2. A solução de trabalho do diurom foi preparada dissolvendo-o previamente em $2 \mathrm{~mL}$ de acetona e completando o volume $\left(\mathrm{v}_{\mathrm{f}}=100\right.$ $\mathrm{mL}$ ) com água. A suspensão do sulfato de endossulfam foi preparada dissolvendo-o previamente em $2 \mathrm{~mL}$ de etanol e aproximadamente $100 \mathrm{~mL}$ de água. As soluções e suspensões de trabalho foram mantidas sob refrigeração $\left(6{ }^{\circ} \mathrm{C}\right)$. A suspensão do sulfato de endossulfam foi aquecida a $\sim 40{ }^{\circ} \mathrm{C}$ em banho-maria no momento da sua utilização para garantir completa solubilização.

Tabela 2. Estruturas e principais propriedades físicas e químicas do sulfato de endossulfam e do diurom. Retiradas das refs. 26 e 51

\begin{tabular}{|c|c|c|}
\hline & Sulfato de endossulfam & Diurom \\
\hline $\begin{array}{l}\text { Nome químico } \\
\text { (CAS) }\end{array}$ & $\begin{array}{c}\text { 6,7,8,9,10-hexachloro- } \\
\text { 1,5,5a,6,9,9a-hexahydro- } \\
\text { 6,9-methano-2,4,3-benzo- } \\
\text { dioxathiepin-3,3-dioxide }\end{array}$ & $\begin{array}{l}N^{\prime} \text {-(3,4-dichlorophenyl)- } \\
\quad N, N \text {-dimethylurea }\end{array}$ \\
\hline Grupo químico & clorociclodieno & uréia \\
\hline $\begin{array}{l}\text { Massa molar } \\
\left(\mathrm{g} \mathrm{mol}^{-1}\right)\end{array}$ & 422,9 & 233,11 \\
\hline $\begin{array}{l}\text { Solubilidade em } \\
\text { água }\left(\mathrm{mg} \mathrm{L}^{-1}\right) \\
\left(25^{\circ} \mathrm{C}\right)\end{array}$ & 0,22 & 42 \\
\hline $\begin{array}{l}\text { Pressão de vapor } \\
(\mathrm{mm} \mathrm{Hg})\left(25^{\circ} \mathrm{C}\right)\end{array}$ & $1 \times 10^{-5}$ & $8,25 \times 10^{-9}$ \\
\hline $\log \mathrm{K}_{\mathrm{ow}}$ & 3,66 & 2,85 \\
\hline $\begin{array}{l}\text { Tempo de meia } \\
\text { vida (d) }\end{array}$ & - & 90 \\
\hline $\begin{array}{l}\text { Estrutura } \\
\text { molecular }\end{array}$ & & \\
\hline
\end{tabular}

-: dado não disponível.

\section{Estudo de degradação}

O estudo de degradação, realizado em condições controladas de temperatura e umidade do solo, seguiu recomendações do guia da OECD sobre transformações aeróbia e anaeróbia no solo. ${ }^{41} \mathrm{O}$ solo, após ser seco ao ar e peneirado $(2 \mathrm{~mm})$, foi transferido $(50 \mathrm{~g})$ para pequenas caixas de alumínio (dimensões de $8 \times 6 \mathrm{~cm}$, altura $3 \mathrm{~cm}$ ).

Alíquotas da solução e da suspensão de trabalho das substâncias estudadas foram adicionadas, separadamente, ao solo em cada caixa, de modo a fornecer uma concentração de aproximadamente $1 \mu \mathrm{g}$ do 
pesticida por grama de solo (dosagem semelhante à usada no campo). Após a fortificação, as amostras de solo de cada caixa foram revolvidas com espátula de inox para garantir completa homogeneização das mesmas e as caixas fechadas com tampas com 6 furos de $2 \mathrm{~mm}$ cada para manter a condição aeróbica. As amostras foram incubadas na ausência da luz em câmara climática com condições controladas de umidade em 50 e $70 \%$ da capacidade de campo e de temperaturas de 30 e $40{ }^{\circ} \mathrm{C}$. O controle da umidade do solo foi realizado pesando-se as amostras de solo periodicamente e repondo-se as perdas com adição de água deionizada. Os experimentos foram conduzidos por 100 dias em triplicata, sendo os recipientes retirados da câmara climática nos tempos $0,2,4,8,16,32,64$ e 100 dias após a fortificação para análise do diurom e sulfato de endossulfam.

\section{Análise de resíduos do diurom e sulfato de endossulfam no solo}

\section{Análise de resíduos do sulfato de endossulfam no solo}

As análises dos resíduos de sulfato de endossulfam foram realizadas segundo o método descrito por Laabs et al. ${ }^{3}$ Em resumo, uma alíquota de $50 \mathrm{~mL}$ da solução extratora água:acetona:acetato de etila $(1: 2: 2 \mathrm{v} / \mathrm{v} / \mathrm{v})$ foi adicionada a $25 \mathrm{~g}$ de amostra de solo e a mistura foi agitada por $4 \mathrm{~h}$ (agitação horizontal, 90 rpm). Após filtração em papel de filtro, o extrato foi concentrado $\left(40^{\circ} \mathrm{C}, 80 \mathrm{rpm}, 400 \mathrm{mbar}\right)$ a aproximadamente $5 \mathrm{~mL}$ e o concentrado foi transferido para um funil de separação com capacidade de $100 \mathrm{~mL}$ ao qual foram acrescentados $30 \mathrm{~mL}$ de solução aquosa saturada de $\mathrm{NaCl}$. Foram adicionados $25 \mathrm{~mL}$ de diclorometano ao balão de rotavapor (divididos em 3 porções), que após agitação vagarosa foram transferidos para o funil de separação. $O$ funil foi vigorosamente agitado por $10 \mathrm{~min}$, deixando-o em repouso por 10 a 15 min para melhor separação das fases. Após a separação, a fase orgânica foi drenada e transferida para um balão, passando através de um funil com sulfato de sódio anidro. O processo de adição de diclorometano ao funil de decantação, agitação e separação da fase orgânica foi repetido três vezes e as fases orgânicas separadas foram combinadas no balão.

Após concentração até quase secura, o extrato foi retomado com alíquotas de tolueno e transferido para um frasco de amostrador automático ( $2 \mathrm{~mL}$ de capacidade), juntamente com $50 \mu \mathrm{L}$ de padrão interno $\alpha-\mathrm{HCH}$ (concentração aproximada de $100 \mu \mathrm{g} \mathrm{mL}^{-1}$, correspondendo a $\left.2,5 \mu \mathrm{g} \mathrm{mL}{ }^{-1}\right)$. O volume final do extrato, assim como dos padrões do sulfato de endossulfam para a curva analítica $(0,1 ; 0,5 ; 1 ; 5 ; 10$ e 15 $\mu \mathrm{g} \mathrm{mL}{ }^{-1}$ ), foi de aproximadamente $2 \mathrm{~mL}$. O sulfato de endossulfam foi submetido à identificação e quantificação por padronização interna utilizando CG-DCE.

\section{Análise de resíduos do diurom no solo}

O diurom foi identificado pelo seu tempo de retenção e confirmação pelo espectro de UV. A quantificação foi realizada por padronização interna, sendo a terbutilazina utilizada como padrão interno. As análises dos resíduos de diurom foram realizadas segundo o método descrito por Dores et al.. ${ }^{4}$

$\mathrm{O}$ método constituiu de pesagem de $15 \mathrm{~g}$ de solo em um tubo de centrífuga, adição de $40 \mathrm{~mL}$ de solução extratora acetona:acetonitrila:solução de $\mathrm{KCl}\left(0,2 \mathrm{~mol} \mathrm{~L}{ }^{-1}\right) / \mathrm{HCl}\left(0,2 \mathrm{~mol} \mathrm{~L}^{-1}\right)$ em pH 2 (2:2:1 v/v/v) e agitação orbital (3:30 h). Em seguida, as amostras foram centrifugadas (1600 rpm), o extrato foi concentrado $\left(45^{\circ} \mathrm{C}, 80 \mathrm{rpm}, 400 \mathrm{mbar}\right)$ e transferido para um béquer de $200 \mathrm{~mL}$ com lavagens sucessivas do balão com $180 \mathrm{~mL}$ de água deionizada. Após ajuste do $\mathrm{pH}$ entre 7,0 e 7,5, o extrato foi purificado utilizando extração em fase sólida com $\operatorname{SDVB}(0,2 \mathrm{~g})$ condicionado previamente com $5 \mathrm{~mL}$ de metanol e $5 \mathrm{~mL}$ de água deionizada. Após a pré-concentração, a eluição do diurom foi realizada com 2 porções de $10 \mathrm{~mL}$ e 1 porção de $5 \mathrm{~mL}$ da mistura metanol:acetonitrila (7:3 $\mathrm{v} / \mathrm{v})$. O extrato final foi concentrado em evaporador rotatório até quase a secura, retomado em acetonitrila e transferido para um frasco de amostrador automático ( $2 \mathrm{~mL}$ de capacidade), juntamente com $50 \mu \mathrm{L}$ de padrão interno terbutilazina (concentração aproximada de $100 \mu \mathrm{g}$ $\mathrm{mL}^{-1}$, correspondendo a aproximadamente $2,5 \mu \mathrm{g} \mathrm{mL} \mathrm{mL}^{-1}$ ) e submetido à análise cromatográfica. $\mathrm{O}$ volume final do extrato, assim como os dos padrões do diurom para a curva analítica $(0,1 ; 0,3 ; 0,5 ; 1 ; 3 ; 5$; 10; 20 e $30 \mu \mathrm{g} \mathrm{mL}^{-1}$ ), foi de aproximadamente $2 \mathrm{~mL}$.

\section{Tratamento dos dados}

Os resultados das porcentagens remanescentes dos pesticidas no solo em função do tempo foram ajustados a equações de degradação exponencial usando o Software Sigma Plot 9.0. Modelos de decaimento mono (Equação 1) e bi-exponencial (Equação 2) foram avaliados para descrever a cinética de degradação do pesticida diurom e do metabólito sulfato de endossulfam nas diferentes camadas e condições de temperatura e de umidade do solo estudadas.

$$
\begin{gathered}
C_{t}=C_{0} \cdot \exp (-k \cdot t) \\
C_{t}=C_{1} \cdot \exp \left(-k_{1} \cdot t\right)+C_{2} \cdot \exp \left(-k_{2} \cdot t\right)
\end{gathered}
$$

onde $\mathrm{t}$ representa o tempo, $\mathrm{C}_{\mathrm{t}}$ a concentração do pesticida ainda presente no solo no tempo t, $\mathrm{C}_{0}$ a concentração inicial do pesticida no solo, $\mathrm{C}_{1}$ e $\mathrm{C}_{2}$ são frações da concentração inicial do pesticida, $\mathrm{k}_{1}$ e $\mathrm{k}_{2}$ são constantes da taxa de degradação $\left(\mathrm{k}_{1}>\mathrm{k}_{2}\right)$.

A escolha da curva que melhor se ajustou aos dados obtidos foi feita com base nos valores de coeficiente de correlação. A partir das equações foram determinados os $\mathrm{t}_{0.5}$, (no caso do modelo monoexponencial) ou $\mathrm{t}_{0.5}, \mathrm{t}_{0.75}$ e $\mathrm{t}_{0.9}$ (no caso do modelo bi-exponencial), que correspondem ao tempo necessário para que 50, 75 e $90 \%$ da quantidade aplicada do pesticida seja degradada, respectivamente.

\section{RESULTADOS E DISCUSSÃO}

Os limites de detecção e quantificação do método utilizado para o sulfato de endossulfam foram 1 e $4 \mu \mathrm{g} \mathrm{kg}^{-1}$, respectivamente, com intervalo de recuperação entre 85 e $110 \% .^{3}$ Para o diurom, os limites de detecção e quantificação do método foram 3 e $10 \mu \mathrm{g} \mathrm{kg}^{-1}$, respectivamente, com intervalo de recuperação entre 84 e $102 \% .{ }^{4} \mathrm{~A}$ precisão dos métodos foi considerada satisfatória, sendo o coeficiente de variação menor do que $20 \%$.

Os resultados do estudo de degradação do sulfato de endossulfam e do diurom, obtidos para a maioria das condições estudadas, foram melhor descritos pelo uso do modelo de decaimento bi-exponencial. Esse modelo descreve uma degradação bifásica, ou seja, um comportamento de degradação em que ocorre um rápido declínio inicial na concentração do pesticida em um curto intervalo de tempo, seguida por uma taxa de redução mais lenta. Essa segunda fase de degradação, mais lenta, pode ser atribuída a uma fração de pesticida fortemente sorvido e que pode estar menos acessível aos processos de degradação. ${ }^{3}$

Para os dados que se ajustaram a uma equação mono-exponencial foi apresentado somente o tempo de meia-vida, entretanto para o bi-exponencial, foram calculados os tempos de degradação de 75 e $90 \%$, uma vez que estes são fortemente afetados pela segunda fase da degradação, que em geral foi muito mais lenta como pode ser observado comparando os valores de $\mathrm{k}_{1} \mathrm{e}_{2}$.

\section{Degradação do sulfato de endossulfam}

Os parâmetros ajustados do modelo de degradação exponencial para cada camada de solo e condições de temperatura e de umidade 
Tabela 3. Parâmetros de degradação do sulfato de endossulfam nas camadas de 0-30, 30-38, 38-83 cm do Latossolo Amarelo em diferentes condições de temperatura e umidade $\left(\mathrm{C}_{1}\right.$ e $\mathrm{C}_{2}$ expressas em termos de porcentagem da concentração inicial)

\begin{tabular}{|c|c|c|c|c|c|c|c|c|c|c|}
\hline \multirow{2}{*}{$\begin{array}{l}\text { Camada } \\
(\mathrm{cm})\end{array}$} & \multirow{2}{*}{$\begin{array}{c}\text { Temperatura } \\
\left({ }^{\circ} \mathrm{C}\right)\end{array}$} & \multirow{2}{*}{$\begin{array}{l}\text { Umidade } \\
(\%)\end{array}$} & \multicolumn{3}{|c|}{ Degradação $(\mathrm{d})^{*}$} & \multicolumn{4}{|c|}{ Parâmetros da curva de degradação } & \multirow{2}{*}{$\begin{array}{l}\text { Qualidade do Ajuste } \\
\qquad \mathrm{R}^{2}\end{array}$} \\
\hline & & & $\mathrm{t}_{0.5}$ & $\mathrm{t}_{0.75}$ & $\mathrm{t}_{0.9}$ & $\mathrm{C}_{1}$ & $\mathrm{k}_{1}$ & $\mathrm{C}_{2}$ & $\mathrm{k}_{2}$ & \\
\hline \multirow[t]{4}{*}{$0-30$} & 30 & 50 & $87,7^{* *}$ & - & - & 99,44 & 0,0079 & - & - & 0,9578 \\
\hline & & 70 & 40 & 111 & 204 & 25,78 & 0,2351 & 74,11 & 0,0098 & 0,9992 \\
\hline & 40 & 50 & 6,3 & 72 & 213 & 59,91 & 0,2579 & 40,07 & 0,0065 & 0,9813 \\
\hline & & 70 & $26,1^{* *}$ & - & - & 103,48 & 0,0266 & - & - & 0,9910 \\
\hline \multirow[t]{4}{*}{$30-38$} & 30 & 50 & 18,7 & 40,8 & 142 & 91,26 & 0,0440 & 9,87 & $6,7846 \mathrm{E}-10$ & 0,9940 \\
\hline & & 70 & $66,6^{* *}$ & - & - & 98,71 & 0,0104 & - & - & 0,9822 \\
\hline & 40 & 50 & $13,2^{* *}$ & - & - & 92,93 & 0,0525 & - & - & 0,9138 \\
\hline & & 70 & 9,5 & 27,3 & 85,8 & 70,43 & 0,1291 & 33,75 & 0,0142 & 0,9505 \\
\hline \multirow[t]{4}{*}{$38-83$} & 30 & 50 & $22,3^{* *}$ & - & - & 96,41 & 0,0311 & - & - & 0,9380 \\
\hline & & 70 & 44,5 & 106,5 & 188 & 17,69 & 1,913 & 82,31 & 0,0112 & 0,9880 \\
\hline & 40 & 50 & 3,2 & 25,3 & 59 & 50,92 & 0,7638 & 49,73 & 0,0272 & 0,9315 \\
\hline & & 70 & $17,3^{* *}$ & _ & _ & 95,02 & 0,0401 & _ & - & 0,9728 \\
\hline
\end{tabular}

$* \mathrm{t}_{0,5} ; \mathrm{t}_{0,75} \mathrm{et}_{0,9}=$ tempo necessário para degradação de 50,75 e $90 \%$ da concentração inicial do sulfato de endossulfam, respectivamente. ${ }^{* *}$ Ajuste mono-exponencial.

estudadas para o metabólito sulfato de endossulfam estão apresentados na Tabela 3. Não se observou nenhum padrão de degradação (mono ou bi-exponencial) para mesmas temperaturas, umidades ou camadas do solo, sendo estes bastante variáveis.

Influência da umidade do solo sobre a degradação do sulfato de endossulfam

De modo geral, verificou-se que a persistência do sulfato de endossulfam foi maior na condição de umidade mais elevada $(70 \%$ de umidade), exceto na camada de $0-30 \mathrm{~cm}$ do solo na temperatura de $30^{\circ} \mathrm{C}$.

Observou-se que houve diferença na velocidade de degradação do sulfato de endossulfam entre os dois níveis de umidade, com exceção da camada de $30-38 \mathrm{~cm}$ do solo a $40{ }^{\circ} \mathrm{C}$, onde o $t_{0.5}$ praticamente não variou. $\mathrm{O}$ valor de $\mathrm{t}_{0.5}$ médio no conteúdo de umidade de $50 \%$ para todas as condições estudadas, diferentes profundidades e temperatura, (25,2 dias) foi $26 \%$ menor quando comparado com a média dos valores de $\mathrm{t}_{0.5}$ obtidos nos experimentos com umidade de $70 \%$.

Essa degradação mais rápida na condição de menor umidade é de certa forma um resultado inesperado, considerando que em umidades menores há uma redução da atividade microbiana e, por consequência, uma menor degradação por via biológica. ${ }^{38}$ Entretanto, em ambientes com muita argila ou matéria orgânica os micro-organismos podem ser adsorvidos, em maior número, à fase sólida, ${ }^{43}$ e como o baixo conteúdo de umidade reduz a quantidade de pesticida na solução do solo, isso pode ocasionar um estímulo à biodegradação, principalmente se a solução do solo tiver baixa concentração de nutrientes. Soma-se a isso, o fato do sulfato de endossulfam possuir uma alta adsorção ao solo, com valores de $\mathrm{K}_{\mathrm{d}}$ variando de 63 a $158 \mathrm{~mL} \mathrm{~g}^{-1}$ para o solo estudado, ${ }^{25}$ e baixa solubilidade em água, em torno de $0,22 \mathrm{mg} \mathrm{L}^{-1},{ }^{26}$ ficando assim mais disponível na fase sólida e podendo ser utilizado como nutriente pelos micro-organismos.

\section{Influência da temperatura do solo sobre a degradação do sulfato de endossulfam}

Para as duas temperaturas estudadas, 30 e $40{ }^{\circ} \mathrm{C}$, verificou-se que a degradação do sulfato de endossulfam foi maior na temperatura de incubação mais elevada.

Observou-se que houve diferença considerável na velocidade de degradação do sulfato de endossulfam, entre as duas temperaturas. Os $t_{0.5}$ do sulfato de endossulfam variaram de 3,2 a 26,1 dias para a temperatura de $40^{\circ} \mathrm{C}$ e estenderam-se de 18,7 até 87,7 dias para a temperatura de $30^{\circ} \mathrm{C} . \mathrm{Ot}_{0.5}$ médio na temperatura de $40^{\circ} \mathrm{C}$ para todas as condições estudadas (12,6 dias) comparado àquele na temperatura de $30{ }^{\circ} \mathrm{C}$ (46,6 dias) foi $73 \%$ menor.

Essa degradação mais rápida na temperatura de $40{ }^{\circ} \mathrm{C}$ pode ser explicada devido ao fato de que em temperaturas mais altas há um aumento da atividade microbiana, que contribui diretamente para a degradação do pesticida. Esses dados corroboram os estudos de Tariq et al., que constataram que temperaturas mais elevadas aceleram a degradação do endossulfam, assim como o de Ghadiri e Rose, que observaram também maior degradação do sulfato de endossulfam em temperaturas mais elevadas. ${ }^{5,6} \mathrm{~A}$ temperatura utilizada no experimento $\left(40^{\circ} \mathrm{C}\right)$ poderia favorecer também a ocorrência de perdas do composto por volatilização. Entretanto, devido à baixa pressão de vapor do sulfato de endossulfam (Tabela 2), essas perdas foram consideradas pouco prováveis, representando uma contribuição insignificante para a cinética de degradação.

Os resultados de tempos de meia-vida obtidos neste estudo podem ser considerados baixos quando comparados com outros estudos, como os de Ghadiri e Rose e Sethunathan et al., ${ }^{5,44}$ que não observaram diminuição significativa na concentração do sulfato de endossulfam após 120 dias da aplicação. Esse fato pode ser justificado devido ao solo utilizado nesse estudo apresentar um histórico de sucessivas aplicações nos últimos 10 anos com o mesmo pesticida. Segundo Rouchaud et al.. ${ }^{45}$ a aplicação frequente do mesmo pesticida durante um longo período favorece uma maior adaptação microbiológica, levando a uma maior biodegradabilidade desse pesticida.

Quando a persistência do sulfato de endossulfam nas diferentes profundidades do solo é avaliada, observa-se uma degradação mais rápida nas camadas mais profundas do solo nas diferentes condições de temperatura e umidade. Esse fato pode ser atribuído ao processo de hidrólise catalisada pela argila, ${ }^{46}$ favorecido pelo aumento da quantidade de argila em profundidade (aumento de 274 a $450 \mathrm{~g} \mathrm{~kg}^{-1}$ - Tabela 1).

\section{Degradação do diurom}

Os parâmetros ajustados do modelo de degradação exponencial para cada camada de solo e condições de temperatura e de umidade estudadas para o herbicida diurom estão apresentados na Tabela 4.

\section{Influência da umidade do solo sobre a degradação do diurom}

$\mathrm{O}$ efeito da umidade na degradação do diurom sob todas as condições estudadas, diferentes temperaturas e profundidade do solo, não mostrou um comportamento regular.

De maneira geral, observou-se que o aumento no conteúdo de umidade exibiu um pequeno efeito positivo na velocidade de degradação do 
Tabela 4. Parâmetros de degradação do diurom nas camadas de 0-30, 30-38, 38-83 cm do Latossolo Amarelo em diferentes condições de temperatura e umidade $\left(\mathrm{C}_{1}\right.$ e $\mathrm{C}_{2}$ expressas em termos de porcentagem da concentração inicial)

\begin{tabular}{|c|c|c|c|c|c|c|c|c|c|c|}
\hline \multirow{2}{*}{$\begin{array}{l}\text { Camada } \\
(\mathrm{cm})\end{array}$} & \multirow{2}{*}{$\begin{array}{c}\text { Temperatura } \\
\left({ }^{\circ} \mathrm{C}\right)\end{array}$} & \multirow[t]{2}{*}{ Umidade $(\%)$} & \multicolumn{3}{|c|}{ Degradação $(d)^{*}$} & \multicolumn{4}{|c|}{ Parâmetros da curva de degradação } & \multirow{2}{*}{$\begin{array}{l}\text { Qualidade do Ajuste } \\
\qquad \mathrm{R}^{2}\end{array}$} \\
\hline & & & $\mathrm{t}_{0.5}$ & $\mathrm{t}_{0.75}$ & $\mathrm{t}_{0.9}$ & $\mathrm{C}_{1}$ & $\mathrm{k}_{1}$ & $\mathrm{C}_{2}$ & $\mathrm{k}_{2}$ & \\
\hline \multirow[t]{4}{*}{$0-30$} & 30 & 50 & 4,2 & 62,5 & 160 & 56,39 & 0,4931 & 44,65 & 0,0093 & 0,9666 \\
\hline & & 70 & $30,0^{* *}$ & - & - & 122,04 & 0,0231 & - & - & 0,8796 \\
\hline & 40 & 50 & 25 & 154 & 326 & 43,14 & 0,1975 & 56,74 & 0,0053 & 0,9950 \\
\hline & & 70 & $63^{* *}$ & - & - & 94,49 & 0,0110 & - & - & 0,8981 \\
\hline \multirow[t]{4}{*}{$30-38$} & 30 & 50 & 65 & 304 & 620 & 40,36 & 0,4391 & 60,38 & 0,0029 & 0,9270 \\
\hline & & 70 & 4,8 & 24,3 & 87,5 & 70,13 & 0,2969 & 35,54 & 0,0145 & 0,9162 \\
\hline & 40 & 50 & 182 & 759 & 1520 & 40,99 & 0,0512 & 62,21 & 0,0012 & 0,9155 \\
\hline & & 70 & 185 & 404 & 980 & 90,03 & 0,0042 & 8,53 & $5,0531 \mathrm{E}-10$ & 0,9839 \\
\hline \multirow[t]{4}{*}{$38-83$} & 30 & 50 & 71,5 & 187 & 340 & 23,54 & 0,569 & 76,81 & 0,006 & 0,9679 \\
\hline & & 70 & $8^{* *}$ & - & - & 115,35 & 0,087 & - & - & 0,9414 \\
\hline & 40 & 50 & 153,5 & 331,5 & 566 & 11,94 & 0,103 & 91,01 & 0,0039 & 0,8657 \\
\hline & & 70 & $110^{* *}$ & - & - & 93,0 & 0,0063 & - & - & 0,8497 \\
\hline
\end{tabular}

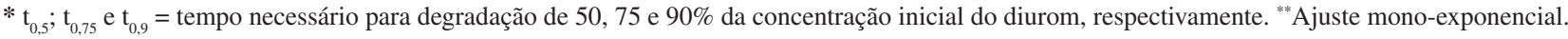

diurom. O valor de $\mathrm{t}_{0.5}$ médio obtido com conteúdo de umidade de $70 \%$ para todas as condiçốes de temperatura e profundidade do solo estudadas (66,8 dias) foi $20 \%$ menor quando comparado com o conteúdo de umidade de 50\% (83,5 dias). Essa degradação mais rápida na condição de maior umidade pode ser explicada pelo fato de que em condições de maior umidade há um aumento da comunidade e atividade microbiana,${ }^{47}$ por consequência, uma maior degradação por via biológica. É importante ressaltar que Giacomazzi e Cochet apresentam a biodegradação como a principal via de degradação do diurom. ${ }^{48}$ Caracciolo et al. também demonstraram a importância dos micro-organismos na degradação do diurom comparando a degradação desse pesticida em solo esterilizado e não esterilizado. ${ }^{7}$ Esses autores observaram maior degradação no solo com atividade microbiológica, obtendo um valor de tempo de meia-vida de 15 dias nesse solo, já nos solos esterilizados o tempo de meia-vida foi por volta de 8 vezes maior $\left(\mathrm{t}_{0.5}=129\right.$ dias $)$.

Degradação mais lenta do diurom foi observada nas camadas mais profundas do solo $(38-83 \mathrm{~cm})$ para as duas condições de umidade e temperatura estudadas, com exceção da condição de $70 \%$ de umidade e $30{ }^{\circ} \mathrm{C}$. Em sub-superfície há uma redução da comunidade microbiana no solo, o que explica a degradação mais lenta.

\section{Influência da temperatura do solo sobre a degradação do diurom}

Para as duas temperaturas estudadas, 30 e $40{ }^{\circ} \mathrm{C}$, verificou-se que a degradação do diurom foi maior na temperatura de incubação mais baixa.

Observou-se que houve diferença considerável na velocidade de degradação do diurom entre as duas temperaturas. Os $\mathrm{t}_{0.5}$ do diurom foram de 4,2 a 71,5 dias para a temperatura de $30^{\circ} \mathrm{C}$ e estenderamse de 25 até 185 dias para a temperatura de $40{ }^{\circ} \mathrm{C}$. $\mathrm{O}$ valor de $\mathrm{t}_{0.5}$ médio na temperatura de $30{ }^{\circ} \mathrm{C}$ para todas as condições de umidade e profundidade de solo estudadas (30,6 dias) foi 74,4\% menor quando comparado com o valor médio obtido na temperatura de $40{ }^{\circ} \mathrm{C}$ (119,5 dias).

Os micro-organismos crescem numa ampla faixa de temperatura e cada um possui uma faixa de temperatura ótima de crescimento que os distingue fisiologicamente. Segundo Perry, ${ }^{49}$ os micro-organismos mesofílicos, que são os mais difundidos, podem crescer entre 20-40 ${ }^{\circ} \mathrm{C}$, mas a temperatura ótima de crescimento é em torno de $32{ }^{\circ} \mathrm{C}$, ou seja, nessa faixa de temperatura a eficiência do crescimento microbiano é máxima, o que justifica a degradação mais rápida do diurom na temperatura de $30^{\circ} \mathrm{C}$, uma vez que, outros estudos realizados já demonstraram que a degradação microbiológica parece ser a principal causa de degradação do diurom. ${ }^{7,48,50}$
Observou-se também no caso da temperatura, assim como para o da umidade, uma diminuição da velocidade de degradação do diurom nas camadas mais profundas do solo, mas não de uma maneira regular. Esse fato poder ser justificado também devido à redução da comunidade microbiana no solo em sub-superfície, o que favorece uma degradação mais lenta.

Rouchaud et al. estudaram a dissipação do diurom em solo e compararam a degradação desse herbicida na superfície do solo em uma parcela com histórico de aplicação do diurom (aplicações sucessivas durante 12 anos), com outra parcela com apenas uma aplicação. ${ }^{45}$ Esses autores constataram um tempo de meia-vida de 81 dias para o diurom no solo sem aplicações no passado e, no solo que tinha um histórico de aplicações, o tempo de meia-vida foi de 37 dias. Os mesmos concluíram que a aplicação frequente do pesticida durante um longo período favorece uma maior adaptação microbiológica, levando com isso a uma maior biodegradabilidade desse pesticida.

Em relação aos tempos de meia-vida determinados no presente estudo, para a camada superficial do solo, os valores estão na faixa do resultado encontrado pelos autores anteriormente citados, uma vez que o solo estudado também apresenta um histórico de sucessivas aplicações do diurom nos últimos 10 anos. Para a condição de $40{ }^{\circ} \mathrm{Ce}$ $70 \%$ de umidade foi observado um valor um pouco superior (63 dias) ao reportado por Rouchaud et al.,${ }^{45}$ mas que pode ser justificado pelo fato de que o trabalho citado foi realizado em campo, enquanto que o presente estudo foi realizado em condições controladas de laboratório, onde os tempos de meia-vida são geralmente maiores devido à ausência de outros mecanismos de dissipação além da degradação. ${ }^{40}$

\section{Comparação do comportamento do diurom com o do sulfato de endossulfam}

Observou-se que para o diurom as condições de maior umidade, temperatura mais baixa e camadas superficiais do solo favoreceram sua degradação. Já para o sulfato de endossulfam o comportamento oposto foi verificado.

O diurom é um herbicida que possui uma moderada solubilidade em água $\left(42 \mathrm{mg} \mathrm{L}^{-1}\right)^{51} \mathrm{e}$ também moderada sorção ao solo $\left(\mathrm{K}_{\mathrm{d}}\right.$ variando de 1,4 a 14,3 mL g ${ }^{-1}$ nas camadas do solo estudado). ${ }^{4}$ Em contraste ao diurom, o sulfato de endossulfam é relativamente insolúvel em água $\left(0,22 \mathrm{mg} \mathrm{L}^{-1}\right)^{26}$ e possui elevada adsorção ao solo, com valores de $\mathrm{K}_{\mathrm{d}}$ variando de 63 a $158 \mathrm{~mL} \mathrm{~g}^{-1}$ para o solo estudado..$^{25}$

Essas propriedades físicas e químicas contrastantes do diurom e do sulfato de endossulfam foram provavelmente as principais 
responsáveis pela diferença de comportamento observada para esses compostos.

Os menores coeficientes de sorção do diurom ao solo em comparação com o sulfato de endossulfam resultaram em maior disponibilidade do primeiro para ser degradado na solução do solo. Além disso, a moderada solubilidade em água do diurom quando comparada ao do sulfato de endossulfam pode ter contribuído para aumentar a sua disponibilidade na solução do solo, favorecendo assim a degradação por via microbiológica que, como mencionado anteriormente, parece ser a principal via de degradação do diurom. . $^{7,48}$

Como o sulfato de endossulfam é fortemente sorvido ao solo e é muito pouco solúvel em água, ${ }^{25,26}$ este metabólito provavelmente ficou mais disponível na fase sólida, podendo ter sido utilizado como nutriente pelos micro-organismos e ocasionando, assim, um estímulo à biodegradação nessa fase. Soma-se a isto o fato de que, estando sorvido ao solo, pode ter ocorrido também a hidrólise catalisada pela argila, ${ }^{46}$ diferentemente do diurom que fica mais disponível na solução do solo.

\section{CONCLUSÕES}

O sulfato de endossulfam foi degradado mais rapidamente em condições de menor umidade $(50 \%)$, temperatura mais elevada $\left(40{ }^{\circ} \mathrm{C}\right)$ e camadas mais profundas do solo $(38-83 \mathrm{~cm})$. Para o diurom as condições de maior umidade $(70 \%)$, temperatura mais baixa $\left(30{ }^{\circ} \mathrm{C}\right)$ e camadas superficiais do solo $(0-30 \mathrm{~cm})$ favoreceram sua degradação. Os comportamentos opostos do diurom e do sulfato de endossulfam foram, em grande parte, consequência das diferenças nas propriedades físicas e químicas desses compostos, em especial ao coeficiente de sorção ao solo e solubilidade.

Tanto o diurom quanto o sulfato de endossulfam foram provavelmente afetados pelo processo de biodegradação acelerada, consequência do histórico de sucessivas aplicações nos últimos 10 anos com diurom e a substância parental do sulfato de endossulfam, endossulfam, no solo estudado.

Esses resultados alertam para interpretações equivocadas que se podem fazer quando generalizações sobre a dinâmica de diferentes condições e moléculas, tanto pesticidas quanto produtos de degradação, são feitas no ambiente, em particular no solo. Esse trabalho também ressalta a necessidade de mais estudos para explicar essas diferenças de comportamento e a inclusão de outros produtos de degradação, que podem ser mais tóxicos e persistentes do que o produto de partida, como é o caso do 3,4-DCA, principal produto de degradação do diurom.

\section{REFERÊNCIAS}

1. http://www.ibge.gov.br/home/estatistica/indicadores/agropecuaria/lspa/ 1spa_200907comentarios.pdf, acessada em Agosto 2009 e Julho 2010.

2. Sabik, H.; Jeannot, R.; Rondeau, B.; J. Chromatogr., A 2000, 885, 217.

3. Laabs, V.; Amelung, W.; Pinto, A. A.; Altstaedt, A.; Zech, W.; Chemosphere 2000, 41, 1441.

4. Dores, E. F. G. C.; Spadotto, C. A.; Weber, O. L. S.; Carbo, L.; Vecchiato, A. B.; Pinto, A. A.; Water Air Soil Pollut. 2009, 197, 175.

5. Ghadiri, H.; Rose, C. W.; J. Environ. Manag. 2001, 62, 155.

6. Tariq, M. I.; Afzal, S.; Hussain, I.; Environ. Res. 2006, 100, 184.

7. Caracciolo, A. B.; Giuliano, G.; Grenni, P.; Guzzella, L.; Pozzoni, F.; Bottoni, P.; Fava, L.; Crobe, A.; Orru, M.; Funari, E.; Environ. Pollut. 2005, 134, 525.

8. http://www4.anvisa.gov.br/AGROSIA/asp/frm_dados_ingrediente. asp?iVarAux=1\&CodIng=155, acessada em Agosto 2009 e Julho 2010.

9. Holland, M. G. Em Goldfrank's Toxicologic Emergencies; Goldfrank, L. R.; Flomenbaum, N. E.; Lewin, N. A.; Howland, M. A.; Hoffman, R. S.; Nelson, L. S., eds.; McGraw-Hill: New York, 2002, cap. 13.
10. Robey, W. C.; Meggs, W. J. Em Emergency Medicine: A Comprehensive Study Guide; Tintinalli, J. E.; Kelen, G. D.; Stopczyski, J. S., eds.; McGraw-Hill: New York, 2000, cap. 17.

11. http://chm.pops.int/Convention/POPsReviewCommittee/ hrPOPRCMeetings/POPRC4/POPRC4Followupcommunications/Invit ationtocommentsondraftriskprofile/tabid/534/language/en-US/Default. aspx, acessada em Agosto 2009 e Julho 2010.

12. Salvestrini, S.; Di Cerbo, P.; Capasso, S.; Chemosphere 2002, 48, 69.

13. Okamura, H.; Chemosphere 2002, 48, 43.

14. Wauchope, R. D.; Buttler, T. M.; Hornsby, A. G.; Augustijn-Beckers, P. W. M.; Burt, J. P.; Rev. Environ. Contam. Toxicol. 1992, 123, 1.

15. Gonzalez-Pradas, E.; Villafranca-Sanchez, M.; Fernandez-Perez, M.; Socias-Viciana, M.; Urena-Amate, M. D.; Water Res. 1998, 32, 2814.

16. Fava, L.; Orru, M. A.; Businelli, D.; Scardala, S.; Funari, E.; Environ. Sci. Pollut. Res. 2006, 13, 386.

17. http://www4.anvisa.gov.br/AGROSIA/asp/frm_dados_ingrediente. asp?iVarAux=1\&CodIng=151, acessada em Dezembro 2009 e Julho 2010.

18. Lapworth, D. J.; Gooddy, D. C.; Environ. Pollut. 2006, 144, 1031.

19. Bacigalupo, M. A.; Meroni, G.; J. Agric. Food Chem. 2007, 55, 3823.

20. Field, J. A.; Reed, R. L.; Sawyer, T. E.; Martinez, M.; J. Agric. Food Chem. 1997, 45, 3897.

21. Awasthi, N.; Ahuja, R.; Kumar, A.; Soil Biol. Biochem. 2000, 32, 1697.

22. Kennedy, I. R.; Sanchez-Bayo, F.; Kimber, S. W.; Hugo, L.; Ahmad, N.; J. Environ. Qual. 2001, 30, 683.

23. Leonard, A. W.; Hyne, R. V.; Lim, R. P.; Leigh, K. A.; Le, J.; Beckett, R.; J. Environ. Qual. 2001, 30, 750.

24. White-Stevens, R.; Pesticides in the Environment, Marcel Dekker: New York, 1971.

25. Camarço, R. T.; Seminário de Iniciação Científica da Universidade Federal de Mato Grosso, Cuiabá, Brasil, 2007.

26. http://www.ephc.gov.au/pdf/cs/workshopdocs/15_Pest_Marshall_ Endosulfan.pdf, acessada em Março 2009 e Julho 2010.

27. Dores, E. F. G. C.; Weber, O. L. S.; Vecchiato, A. B.; Shiraiwa, S.; Salomáo, F. X. T.; Cutrim, A. O. C.; Guimarães, S. C.; Rieder, A.; Pinto, A. A.; Pereira, M. J.; Nascimento, A. L.; trabalho não publicado.

28. Dores, E. F. G. C.; Weber, O. L. S.; Vecchiato, A. B.; Shiraiwa, S.; Salomão, F. X. T.; Cutrim, A. O.; Guimarães, S. C.; Rieder, A.; Pinto, A. A.; Pereira, M. J.; Spadotto, C. A.; trabalho não publicado.

29. Woudneh, M. B.; Ou, Z. ; Sekela, M.; Tuominen, T.; Gledhill, M.; J. Environ. Qual. 2009, 38, 940.

30. Malik, A.; Ojha, P.; Singh, K. P.; Environ. Monit. Assess. 2009, 148, 421.

31. Singh, K. P.; Malik, A.; Sinha, S.; Environ. Monit. Assess. 2007, 125, 147.

32. Tuncel, S. G.; Öztas, N. B.; Erduran, M. S.; J. Air Waste Manag. Assoc. 2008, 58,1240 .

33. Leong, K. H.; Benjamin Tan, L. L.; Mustafa, A. M.; Chemosphere 2007, 66, 1153.

34. Gonçalves, C. M.; Esteves, J. C. G. S.; Alpendurada, M. F.; J. Agric. Food Chem. 2007, 55, 6227.

35. Reichenberger, S.; Amelung, W.; Laabs, V.; Pinto, A.; Totsche, K. U.; Zech, W.; Geoderma 2002, 110, 63.

36. Ribeiro, M. L.; Lourencetti, C.; Pereira, S. Y.; De Marchi, M. R. R.; Quim. Nova 2007, 30, 688 .

37. Paraiba, L. C.; Spadotto, C. A.; Chemosphere 2002, 48, 905.

38. Silva, C. M. M. S.; Fay, E. F. Em Agrotóxicos e Ambiente; Silva, C. M. M. S.; Fay, E. F., eds.; Embrapa: Brasília, 2004, cap. 6.

39. Cullington, J. E.; Walker, A.; Soil Biol. Biochem. 1999, 31, 677.

40. Racke, K. D.; Skidmore, M. W.; Hamilton, D. J.; Unsworth, J. B.; Miyamoto, J.; Ohen, S. Z.; Pure Appl. Chem. 1997, 69, 1349.

41. OECD Guideline for the testing of chemicals; Aerobic and anaerobic transformation in soil, Guideline 307, Organisation for Economic Cooperation and Development: Paris, 2002.

42. Paula, J. L.; Duarte, M. N.; Manual de métodos de análise de solo, $2^{\mathrm{a}}$ ed., Embrapa - Centro Nacional de Pesquisa de solos: Rio de Janeiro, 1997. 
43. Alexander, M.; Biodegradation and biorremediation, $2^{\text {nd }}$ ed., Academic: San Diego, 1999.

44. Sethunathan, N.; Megharaj, M.; Chen, Z.; Williams, B. D.; Lewis, G.; Naidu, R.; J. Agric. Food Chem. 2004, 52, 3030.

45. Rouchaud, J.; Neus, O.; Bulcke, R.; Cools, K.; Eelen, H.; Dekkers, T.; Arch. Environ. Contam. Toxicol. 2000, 39, 60.

46. Awasthi, M. D.; Prakash, N. B.; Pestic. Sci. 1997, 50, 1.
47. Werf, H. M. G. van der.; Agric. Ecosystems Environ. 1996, 60, 275.

48. Giacomazzi, S.; Cochet, N.; Chemosphere 2004, 56, 1021.

49. Perry, K. S. P.; Quim. Nova 2004, 27, 293.

50. Bernard, H.; Chabalier, . F.; Chopart, J. L.; Legube, B.; Vauclin, M.; J. Environ. Qual. 2005, 34, 534.

51. http://extoxnet.orst.edu/pips/ghindex.html, acessada em Julho 2009 e Julho 2010. 